\title{
Meanings and Implications of NDEr Transformations: Some Preliminary Findings and Implications
}

\author{
Charles P. Flynn \\ Department of Sociology \\ Miami University of Ohio
}

\begin{abstract}
Though much need remains for research aimed at validating NDEs, research into the transformative effects of NDEs and their possible moral, cultural, social, and political implications is not premature. In this paper the existing literature on these effects is reviewed and summarized, and the results of a preliminary study of NDEr value transformations is reported. The available evidence shows, in decreasing order of saliency: greatly increased concern for others; lessened fear of death and increased belief in an afterlife; increased religious interest and feeling, both non-institutionalized and institutionalized; and lessened desires for material success and approval of others. These preliminary findings are discussed as providing the basis for exploration of possible implications, including the congruency of NDEr value transformations with Kohlberg's theory of moral development; the possibility that the moral blindness associated with political ideologies is transcended by NDErs; and the possibility that NDErs might be harbingers of a more humane future.
\end{abstract}

\section{INTRODUCTION}

The near-death experience began to come to large-scale public attention with the publication in 1975 of Raymond A. Moody, Jr.'s Life After Life. As both a philosopher and a physician, Moody pointed out some of the philosophical and theological implications of his research in a subsequent work, Reflections on Life After Life. With some exceptions, the attention directed toward both these books tended to be focused on what I will term validation. Since belief in life after death tends to contradict so radically the predominantly positivistic, secular orientation of modern science, and much of modern culture as a whole, the predominant emphasis of near-death research has been on the validation of the NDE accounts, rather than their implications.

This, no doubt, is as it should be, since the exploration of any implications of NDEs must rest upon a firm foundation of rigorous research aimed at all possible non-supernaturally based explanations for the phenomenon. 
Hence, a good deal of the subsequent works have emphasized methods more scientific than Moody's. Kenneth Ring's Life at Death (1980) stressed the application of statistical methods to samples of NDErs, and Michael Sabom's Recollections of Death (1982) brought the prestige, scientific rigor, and skill of a cardiologist to the examination of the phenomenon. A program of research formulated at a 1981 conference of the International Association for Near-Death Studies has also focused on even more rigorous examination of the NDE itself.

But despite the need for such study, we may have reached a stage where tentative explorations of its meaning can begin. Indeed, such explorations need not await the full validation of the experience. The studies thus far have unequivocally shown that regardless of whether or not they are actual journeys into the beginnings of life after physical death, NDEs have strong effects on those who experience them. Thus, in the words of sociologist W. I. Thomas, "things are real when they are real in their consequences." This is particularly true with respect to the NDE:

Such experiences ... tend to exert a powerful effect on a person's motivations, values, and conduct . . . However one chooses to interpret neardeath phenomena, they are unquestionably real in their effects (Ring, 1980, p. 138).

As a humanistic sociologist concerned with social and political orientations and values, I am primarily interested in the value-related changes experienced by NDErs. The existing literature focuses on validation and thus contains relatively little research on such transformations. Such evidence that exists, however, does strongly suggest that NDEs may have substantial social, moral, cultural, and even political implications. Although extrapolation upon limited evidence is undoubtedly premature, I nonetheless believe we may begin to speculate on the possible general character of such implications. This paper will use the existing evidence to set forth in broad outline some of the directions in which the exploration of the meaning of NDEs may eventually lead.

Nature and Types of Social Value Transformations of NDErs

The published evidence, plus some additional research presented here for the first time, shows that NDErs undergo substantial value transformations.

Experiencers resume life by living it more fully, loving more openly, and fearing death less, if at all ... Their life seems more grounded in a sense of 
purpose and is more consciously shaped by the spiritual values of love, compassion, and acceptance (Ring, 1980, p. 203).

The life-review experienced by some, but by no means all, NDErs seems to be a foundation for such value transformations. One $\mathrm{NDEr}$ who had a series of deep experiences stresses the profound impact of the life-review:

The reliving included not only the deeds committed by [me] since birth ... but also a reliving of every thought ever thought and every word ever spoken PLUS the effect of every thought, word, and deed upon everyone and anyone who had ever come within [my] sphere of influence whether I actually knew them or not ... I never before realized that we were responsible and accountable for EVERY SINGLE THING WE DID. That was overwhelming (Atwater, 1980, p. 22)! (Emphasis in original.)

The life-review involves a substantial transformation that deemphasizes values related to conventional definitions of success: money, accomplishments, etc., and stresses kindness, compassion, and unconditional love for others. In the words of another NDEr:

The superficial aspects of my life, what I had accomplished, owned, and known, were consumed [and rendered unimportant]. However, those acts in which I selflessly expressed love or concern for my fellow men were glorified and permanently inscribed in the ... record, with total disregard for however humble or fleeting those moments had been (Pasarow, 1981, p. 11).

Likewise, Moody's respondents indicated that witnessing those events in which they had shown love and kindness brought satisfaction (Moody, 1977, p. 32).

Closely associated with the centrality of love and kindness toward others is a devaluation of materialistic goals. Ring's respondents indicated a decreased emphasis on money and material things in general:

'I value people more. I don't think I value worldly goods that much.'

'I feel so totally different about . . . material things. They're so unimportant to me [now]' (Ring, 1980, pp. 143-144).

Michael Sabom's recent book, Recollections of Death (1982), also reports an anti-materialistic value orientation among his subjects. As one NDEr told him:

'Well, I don't think anybody would mind being prosperous, but I see how little it really does mean ... I found out that some of these things are really laughable as far as importance. So all I need now, in my way of thinking, is to be able to survive comfortably' (Sabom, 1982, p. 132). 
Russell Noyes also reports that some of his respondents reevaluated their priorities. One said that his values had become more "humanoriented," another that since her experience she has " "valued people much more than material things" "(1980, p. 238).

Another type of transformation common among NDErs is a greater willingness to accept others. The usual social boundaries and categories: sex, race, age, status, etc., are removed, and the inherent equality of all people is recognized and affirmed. Along with this, many NDErs report lessening of prejudicial attitudes. As one puts it,

How can one friend mean any more than another when everyone is your friend and there are no strangers? Every child becomes your child. Every man your husband, father and brother. Every woman your wife, mother and sister. Boundaries and blood lines, barriers and taboos cease. For the survivor, there are no more divisions, races, religions, nationalities or separations of any kind. Love has expanded outward and it doesn't quit growing (Atwater, 1981, p. 6).

Associated with this breakdown of boundaries is a less judgmental approach to others. As one of Ring's respondents said,

'It's given me tolerance. It's made me less judgmental' (Ring, 1980, p. 156).

Overriding all of these transformations is a much greater concern for others. The goal of the NDEr's life shifts from selfish concerns to a desire to help others. As another of Ring's respondents emphasizes:

'Fulfilling yourself with . . . love - by giving. As much as by getting ... in the way of recognizing that we're all in the same boat and we all have weaknesses and we all have strengths, and to help is where it's at' (Ring, 1980, p. 145).

In addition to the interview-based material discussed above, more systematic support for the nature and extent of NDErs' value transformations has begun to be available. In an analysis of data obtained through a questionnaire administered by Kenneth Ring, I found the general types of transformations described in the existing literature tended to be supported by the survey results. Though the number of subjects, 21 , is small, these preliminary results suggest a common pattern of value transformations commensurate with the existing interview-based material.

The survey results show that above all else, including even reduced fear of death, NDErs report a strong increase in concern for others. This factor, comprised of questions pertaining to desire to help others, compassion, patience, tolerance, empathy, and understanding and acceptance of others, increased strongly or somewhat in the sub- 
Table I

POST-NDE CHANGES

(21 Cases)

\begin{tabular}{|c|c|c|c|c|c|}
\hline & $\begin{array}{l}\quad \mathbf{N} \\
\text { Strongly } \\
\text { Increase }\end{array}$ & $\begin{array}{c}\mathbf{N} \\
\text { Increase } \\
\text { Somewhat }\end{array}$ & $\begin{array}{c}\text { N } \\
\text { No } \\
\text { Change }\end{array}$ & $\begin{array}{c}\mathbf{N} \\
\text { Somewhat } \\
\text { Decrease }\end{array}$ & $\begin{array}{c}\mathbf{N} \\
\text { Strongly } \\
\text { Decrease }\end{array}$ \\
\hline $\begin{array}{l}\text { Factor I: } \\
\text { Concern for Others } \\
\text { Desire to Help Others } \\
\text { Compassion for Others } \\
\text { Ability to Listen Patiently } \\
\text { Tolerance for Others } \\
\text { Insight In to Others } \\
\text { Understanding Others } \\
\text { Acceptance of Others }\end{array}$ & $\begin{array}{l}15 \\
16 \\
15 \\
12 \\
11 \\
10 \\
14\end{array}$ & $\begin{array}{l}3 \\
4 \\
3 \\
5 \\
6 \\
9 \\
4\end{array}$ & $\begin{array}{l}3 \\
1 \\
2 \\
4 \\
4 \\
2 \\
3\end{array}$ & $\begin{array}{l}0 \\
0 \\
1 \\
0 \\
0 \\
0 \\
0\end{array}$ & $\begin{array}{l}0 \\
0 \\
0 \\
0 \\
0 \\
0 \\
0\end{array}$ \\
\hline $\begin{array}{l}\text { Factor II: } \\
\text { Death-Related Attitudes } \\
\text { Fear of Death } \\
\text { Belief in Afterlife } \\
\end{array}$ & $\begin{array}{r}0 \\
19 \\
\end{array}$ & $\begin{array}{l}0 \\
1 \\
\end{array}$ & $\begin{array}{l}0 \\
1 \\
\end{array}$ & $\begin{array}{l}3 \\
0 \\
\end{array}$ & $\begin{array}{r}18 \\
0 \\
\end{array}$ \\
\hline $\begin{array}{l}\text { Factor III: } \\
\text { Subjective Transcendence } \\
\text { Belief that Life has } \\
\text { Inner Meaning } \\
\text { Feeling of Innet } \\
\text { Presence of God } \\
\text { Prente }\end{array}$ & $\begin{array}{l}20 \\
15 \\
\end{array}$ & $\begin{array}{l}0 \\
5\end{array}$ & $\begin{array}{l}1 \\
1\end{array}$ & $\begin{array}{l}0 \\
0\end{array}$ & $\begin{array}{l}0 \\
0\end{array}$ \\
\hline $\begin{array}{l}\text { Factor IV: } \\
\text { Religiosity } \\
\text { Interest in Religion } \\
\text { Religious Feelings } \\
\text { Interest in Sacred Things } \\
\text { Involvement in Prayer } \\
\end{array}$ & $\begin{array}{r}3 \\
11 \\
14 \\
8 \\
\end{array}$ & $\begin{array}{l}6 \\
7 \\
4 \\
9\end{array}$ & $\begin{array}{l}6 \\
2 \\
3 \\
2 \\
\end{array}$ & $\begin{array}{l}2 \\
1 \\
0 \\
2 \\
\end{array}$ & $\begin{array}{l}4 \\
0 \\
0 \\
0 \\
\end{array}$ \\
\hline $\begin{array}{l}\text { Factor V: } \\
\text { Materialism } \\
\text { Desire for Material Things } \\
\text { Desire for High Standard } \\
\text { of Living } \\
\text { Desire for Wealth }\end{array}$ & $\begin{array}{l}0 \\
1 \\
0\end{array}$ & $\begin{array}{l}0 \\
2 \\
0\end{array}$ & $\begin{array}{r}6 \\
9 \\
10\end{array}$ & $\begin{array}{l}7 \\
5 \\
5\end{array}$ & $\begin{array}{l}8 \\
4 \\
6\end{array}$ \\
\hline $\begin{array}{l}\text { Factor VI: } \\
\text { Impression on Others } \\
\text { Desire to Make Good } \\
\text { Impression on Others } \\
\text { Concern About What } \\
\text { Others Think }\end{array}$ & 1 & 2 & 3 & $\begin{array}{l}4 \\
6\end{array}$ & $\begin{array}{l}6 \\
8\end{array}$ \\
\hline
\end{tabular}


stantial majority of cases (an average of 18 of 21 cases), with only one person reporting any decrease in any of the questions comprising the Concern for Others factor.

Closely related to concern for others is the second most salient factor, fear of death, with a substantial majority indicating decrease in such fear together with a strong increase in belief in an afterlife. Closely related to these are four other factors (see Table I) indicating, in decreasing order of significance, increases in belief in an inner meaning of life and an inner experience of God (what I term "subjective transcendence"); somewhat lesser increase of interest in religiosity and religious phenomena; decreased desire for material gain; and decreased need to impress others. In general, these findings substantiate the interview material obtained by Moody, Ring, Sabom, and others.

The findings presented here are certainly not extensive or thorough enough to warrant drawing clearcut implications. Speculation, of course, can be justified when it serves as a fertile source of scientific hypotheses that extend boundaries of present knowledge. It is in this spirit that the remainder of this paper will set forth a number of tentative, general, but, I hope, useful ideas concerning possible implications of the value transformations associated with NDEs. These speculations are interrelated in many respects but for analytic purposes will be dealt with in terms of moral, social and cultural, and political implications.

\section{Morality and the NDE}

Though science is concerned with fact and knowledge, and morality focuses on what ought to be, a number of researchers have begun to use scientific methods in the examination of moral behavior and attitudes. Perhaps the foremost among these is Lawrence Kohlberg of Harvard, who has formulated a theory of moral development.

In the first stage the individual conforms to moral rules out of fear of negative consequences, most commonly fear of being punished. In the second stage the individual acts morally in order to obtain some sort of reward, or in reciprocity for others acting morally toward him rather than out of commitment to moral principles. In the third stage the individual seeks the approval of others and thereby acts morally in what David Reisman would term "otherdirectedness." In the fourth stage the individual develops a belief in values, norms, rules, and regulations associated with the status quo, a kind of law-and-order orientation. In the fifth stage these principles 
extend beyond arbitrarily imposed laws to a morality arrived at through democratic processes and based on moral consensus. At the sixth stage, which in Kohlberg's view is arrived at only by relatively small numbers of exceptional people, moral belief and action are based on a commitment to humanity as a whole and stem from development of conceptions of justice and other abstract principles, such as Kant's categorical imperative and Schweitzer's reverence for life.

In a recent book Kohlberg (1981) has posited a seventh stage in which the universe and existence as a whole become the basis of a cosmic morality. In his words,

[In the seventh stage] our consciousness of justice or moral law is parallel to, or in harmony with, our consciousness of the ultimate power or laws governing the larger extrahuman or cosmic order (Kohlberg, 1981, p. 221).

As a first step in the analysis of the moral consciousness experienced by NDErs, it would be interesting to analyze in depth the kinds of value transformations characteristic of NDErs using Kohlberg's theory and methods as a basic framework. Though the evidence, as we have seen, is now quite fragmentary, it seems safe to postulate that the NDE does provide the basis for significant development of moral consciousness. As one NDEr, Joseph Geraci, stated in a recent interview (1981), however, we should not assume that NDErs have transcended common human weaknesses and failings because they may have been exposed to and been strongly influenced by a "higher" conception of morality. At any rate, the research I am initiating into the effects of NDEs will use Kohlberg's model as one of several ways of scientifically investigating NDEr value transformations.

\section{Ideological and Political Implications}

In addition to Kohlberg's focus on individual moral development, NDEs may also have larger implications. One of the most striking but seldom perceived aspects of opposing moral and political systems is that they sometimes share a core moral assumption. Current ideologies of capitalism and communism, for example, each exhibit the characteristic sociologist Karl Mannheim in his classic work, Ideology and Utopia (1936), referred to as "talking past one another." Despite the fact that the proponents of each ideology see themselves as in virtually total opposition, each accuses the other of certain kinds of negative consequences that, at root, are very similar.

Typically, the Marxist refers to the capitalists' tendency to exploit workers by extracting the value of their surplus labor (over and above what it costs to produce something) and thus obtain profits 
and wealth at the expense of the workers. Under this system, according to Marxist thought, the worker is alienated from his true selfhood because the products of his labor become not something that fulfill him but stand apart from him because their only purpose is to turn into profit for the owners of the means of production. Hence, at the core of the Marxist thought that formed the basis of communist ideology, the capitalist is condemned for using his workers as mere instruments for the fulfillment of his goal of material wealth. Capitalists, on the other hand, base their condemnation of communist systems on the negative consequences that come about as a result of the revolutionary transformation into a communist society. "Free World" apologists maintain that the "masses" become the mere tools of a political elite who control their lives as completely as possible and execute or imprison dissidents who do not conform or who otherwise do not fit into the system.

In both the Communist and capitalist world-views, there are, despite outward differences, shared moral values. Both, in essence, base their case on a shared condemnation of what I will term instrumental morality: the use of some human beings by others in order to gain material and other benefits.

In the implicit criterion of morality apparent in the accounts of NDErs, the life-review involves witnessing the consequences of one's actions in the lives of others. Though he doesn't elaborate on the point, Moody implies that those who are in power may inflict both positive and negative consequences on the lives of many they don't even know.

In his discussion of the possible "punishment" that might be suffered by those who have power and abuse it, Moody suggests that such groups as Nazis who have engineered countless negative consequences in the lives of others will be forced to witness these consequences, a fate in Moody's words of a terrible, unbearable sort.

Likewise, those who have brought about positive consequences in the lives of others by helping them (often in supposedly small, "inconsequential" acts of kindness) will be "rewarded" by witnessing the positive consequences their actions have had in the lives of others.

Thus, one possible implication of NDE value transformations is that they may allow us to synthesize existing but largely unrecognized assumptions concerning morality of even such opposing ideologies as capitalism and Marxism. NDE research suggests that regardless of our religious beliefs, political orientations, etc., we judge ourselves and others, fundamentally, in terms of how positively or negatively we affect others. In sum, the NDE appears to strip 
away artificial definitions of belief (found in existing belief systems) and reveal the universal moral and ethical principle of action-effectconsequence.

Immortality Striving and the NDE

Another factor relevant to possible large-scale implications of NDEs is decreased fear of death. In particular, the work of the late Ernest Becker provides a basis for exploring possible ways in which NDErs' loss of most fear of death may be related to social and political conflict.

As Becker stressed in The Denial of Death (1973) and Escape From Evil (1975), people engage in destructive action in order to overcome the meaninglessness of death. Human beings are plagued with the knowledge of their inevitable death, and much if not all forms of culture can be understood as an effort to overcome death. Moreover, instrumental morality stems from such striving, since "men use one another to assure their personal victory over death" (Becker, 1975, p. 108).

This is apparent in many ways. Wealth gives people a sense that they have power above and beyond their organic capacities that they can use to extend themselves, through various kinds of memorializations and legacies, into the future. The elixir of power, likewise, is distilled from the fruit of the promise of immortality, as are the glory and fame that accrue to the victorious warrior, athlete, or other type of "celebrity."

All forms of immortality offered by culture, however, involve some cost, direct or indirect, for others. The glory of the victorious warlord rests on the corpses of both the defeated enemy and his own warriors. The wealth of the affluent means nothing apart from its contrast with the relative poverty of others. And so on in myriad contexts.

If, as Becker contends, fear of death and desire for immortality are at the root of most forms of evil, one implication is that the NDE may be able to serve as an important foundation for overcoming such evils without creating more evil. Specifically, since the life-review suggests that having positive effects on others' lives and avoiding negative effects is a prime, if not central, value in the post-organic existence, NDErs, if accepted, might become important transmitters of this value-orientation for humanity.

\section{Are NDErs Harbingers of a More Humane Future?}

It is tempting, in this age of imminent threat of nuclear holocaust 
and countless other evils, to view the NDE as a possible means of preventing omnicide, the complete destruction of all life on earth. The value transformations I have described in this paper, and which I hope will be studied in much greater depth and breadth in the future, 1 seem to point the way beyond the ideological impasse which has led us to our current situation. As an anonymous reviewer of the first draft of this paper correctly cautioned, however, ". . . why should a relative handful of near-death survivors succeed where countless saints ... and holy men and women with their extensive followings have repeatedly failed - failed, that is, on a worldwide basis?"

I have long wondered how the pattern of human morality might be changed and long despaired at the seeming insolubility of the task. Yet, I share with Joe Geraci (whose views may indeed reflect the hopes of other NDErs and those concerned with the moral implications of their experiences) the dream he expressed in a recent issue of Vital Signs:

I believe love can be just as infectious as hate. It has to turn around. And to do that, people have to start somewhere. On a small scale, just me telling you about my experience, and someone reading what you're going to write. It multiplies quickly. And I'm not the only one who has had this experience. There are thousands of us all around the world. Multiply my story by a thousand and you'll see how quickly it can grow! It can be done. In fact, it has already started (Geraci, 1981, p. 12).

In order to begin to realize this hope, we need to begin to study the changes in the lives of NDErs in much greater detail than has previously been researched. Specific knowledge is needed concerning such questions as:

1. Are the changes merely attitudinal, or do they involve major transformations in life goals and life directions, evidenced by occupational, marital, or other kinds of measurable changes?

2. Does the increased concern for others experienced by most NDErs lead to concrete patterns of altruistic behavior, such as contributing to and/or volunteering for charitable endeavors?

3. To what extent do NDErs become more concerned with world issues, such as hunger, nuclear war, and other issues pertaining to human suffering?

4. Does the NDE lead to any shifts in political attitudes and values?

5. How do others in NDErs' lives - spouses, children, friends, associates, etc. - view the changes NDErs experience?

These and similar questions need to be addressed if we are to begin to see to what extent the NDE may be the basis of large-scale social, cultural, and/or political transformation, since they are aimed at determining the extent to which actual transformations have 
occurred in the lives not only of NDErs, but in those whose lives they affect. As a sociologist, I am beginning to undertake research on these vital areas of concern with the hope that the knowledge and insight to be obtained may lead to a world in which the caring and compassion existing studies show to be the major consequence of the NDE may eventually become the norm rather than the exception among all people.

\section{NOTES}

1. The author would greatly appreciate any life history or other information concerning NDE-related value transformations.

\section{REFERENCES}

Atwater, P. I Died Three Times in 1977. Harrisonburg, Virginia: Shenandoah Press, 1980.

Atwater, P. Coming back. Vital Signs, 1 (3), 6.

Becker, E. Denial of Death. New York: Free Press, 1973.

Becker, E. Escape From Evil. New York: Free Press, 1975.

Geraci, J., interviewed by Darlene Taylor. Profile of an experiencer: Joe Geraci. Vital Signs, 1981, 1 (3), 3-12.

Kohlberg, L. Philosophy of Moral Development. New York: Harper and Row, 1981.

Mannheim, K. Ideology and Utopia. New York: Harcourt, Brace, 1936.

Moody, R. A., Jr. Life After Life. Atlanta: Mockingbird Books, 1975.

Moody, R. A., Jr. Reflections on Life After Life. New York: Bantam Books, 1977.

Noyes, R. Attitude change following near-death experiences. Psychiatry, 1980, 43, 234-242.

Pasarow, R. A personal account of an NDE. Vital Signs, 1, (3), 11-14. Reisman, D., assisted by Glazer, N., and Denney, R. The Lonely Crowd. New Haven: Yale University Press, 1950.

Ring, K. Life At Death. New York: Coward, McCann and Geoghegan, 1980.

Sabom, M. Recollections of Death. New York: Harper and Row, 1982. 
Request for reprints to:

Charles P. Flynn

Department of Sociology and Anthropology

Miami University

Oxford, Ohio 45056 